\title{
JANE EYRE E O PROJETO IMPERIALISTA: UMA LEITURA CONTRAPONTUAL'
}

\author{
JANY EYRE AND THE IMPERIALIST PROJECT: \\ A CONTRAPUNTAL READING
}

\section{Viviane de Freitas ${ }^{2}$}

\begin{abstract}
Resumo: Este trabalho se propõe a fazer uma "leitura contrapontual" (SAID, 1995) do romance Jane Eyre tendo como foco o projeto imperialista inglês e a posição ocupada pelos personagens Jane Eyre, Rochester e Bertha Mason. O trabalho coloca em primeiro plano a imbricação entre identidade e questões como raça, nacionalidade, classe e gênero, a partir da interlocução com os escritores McLeod (2010), Spivak (1995) e Said (1995). Esse enfoque busca evidenciar o contexto colonial no romance de Charlotte Brontë, os fatores que determinaram a trajetória de progresso da protagonista Jane Eyre e a condição de exílio da personagem caribenha Bertha Mason. O trabalho examina a relação entre a origem colonial de Bertha e o seu (não) lugar tanto na sociedade inglesa quanto no romance inglês do século XIX. Por outro lado, a ascensão social e o prestígio do casal protagonista Jane Eyre e Rochester, bem como a posição de Jane como heroína individualista da ficção britânica do século XIX são abordadas diante do contexto do imperialismo e sua missão civilizatória.
\end{abstract}

Palavras-chave: Jane Eyre. Imperialismo inglês. Leitura contrapontual.

Abstract: This work intends to make a "contrapuntal reading" (SAID, 1995) of the novel Jane Eyre by focusing on the English imperialist project and the position occupied by the characters Jane Eyre, Rochester and Bertha Mason. The work brings to the fore the intertwining of identity and issues such as race, nationality, class and gender, through the interlocution with writers McLeod (2010), Spivak (1995) and Said (1995). This approach seeks to highlight the colonial context in Charlotte Brontë's novel, the factors that determined the protagonist Jane Eyre's trajectory of progress, and the condition of exile of the Caribbean character Bertha Mason. The work examines the relationship between Bertha's colonial origin and her (lack of) place in both English society and the nineteenth-century English novel. On the other hand, the protagonist couple Jane Eyre and Rochester's social ascension and prestige, as well as the position of Jane as the individualist heroine of nineteenth-century British fiction are addressed in the context of imperialism and its civilizing mission.

Keywords: Jane Eyre. British Imperialism. Contrapuntual reading.

Jane Eyre foi escrito pela inglesa Charlotte Brontë no início da década de 1840, e publicado sob o pseudônimo masculino de Currer Bell em $1847^{3}$. O romance é narrado em primeira pessoa pela protagonista Jane Eyre, que conta a sua trajetória desde a infância pobre no orfanato até o seu trabalho como governanta em Thornfield Halls, e finalmente o seu casamento com Edward

\footnotetext{
${ }^{1}$ Este trabalho consiste em um recorte de um dos capítulos da tese intitulada "Cartografias do exílio: errância e espacialidade na ficção da escritora caribenha Jean Rhys" (De FREITAS, 2017) e alguns trechos da abordagem do romance Jane Eyre foram publicados no artigo "O espaço rizomático de Vasto Mar de Sargaços de Jean Rhys" (De FREITAS, 2014).

2 Doutora em Literatura e Cultura pela UFBA. Professora adjunta da UFRB. E-mail: defreitasuk@gmail.com; http://lattes.cnpq.br/9673543220364611

3 O nome verdadeiro da autora é revelado em 1848.
} 
Rochester, dono da propriedade Thornfield e membro alta sociedade ${ }^{4}$. A história acompanha, portanto, a trajetória de progresso e ascensão social da protagonista.O romance vitoriano ficou conhecido pelo pioneirismo em retratar a trajetória de progresso de um sujeito feminino individualista.

Jane Eyre desafiou, de diversas maneiras, as convenções e a moral da sociedade vitoriana conservadora e patriarcal que retratava, assim como as convenções literárias do romance realista. $\mathrm{O}$ fato de ter como protagonista e narradora uma mulher sem família, e oriunda da classe baixa inglesa, possibilitou deslocamentos e perspectivas inusitadas para os padrões da época. De acordo com Sally Minogue, no seu prefácio à edição inglesa citada neste trabalho, as questões morais encontradas pela protagonista, na sua conquista individual por um espaço de autonomia e liberdade, levam Brontë não só a explorar novas formas de conceber a relação sujeito [self - mundo, mas também a desafiar as convenções da própria ficção vitoriana realista na qual o romance se situava (cf. MINOGUE, 1999, p. VII). Minogue também observa que, ao longo do tempo, o romance foi lido por diversas perspectivas - marxista, feminista, psicanalítica, pós-colonialista, e explorado em seus aspectos alegóricos, psicológicos, simbólicos, ou como romance de formação. No entanto, ela adverte que é preciso cautela em relação a leituras que enquadram o romance em abordagens e modelos. Se por um lado eles permitem mergulhos produtivos no romance, por outro, a forma idiossincrática da trajetória de progresso da personagem, assim como a riqueza do texto de Brontë subvertem tais enquadramentos. (cf. MINOGUE, 1999, p. IX)

A luta de Jane para vencer os obstáculos em direção ao seu progresso individual é marcada por conquistas, muitas delas atribuídas a sua inteligência, caráter, senso de justiça, trabalho, determinação, capacidade de superação. O êxito da protagonista é coroado pela sua realização pessoal através de um casamento feliz e apaixonado, além da conquista de riqueza material e prestígio social. A leitura do romance voltada para a figura da protagonista direcionou o foco das críticas de Jane Eyre, que durante muito tempo esteve centrado em abordagens feministas ${ }^{5}$ que a celebravam como protótipo da mulher individualista bem-sucedida.

Entretanto, este trabalho põe esse enfoque em perspectiva ao realizar uma leitura contrapontual $^{6}$ que coloca em primeiro plano as representações culturais coloniais contidas no romance de Charlotte Brontë, especialmente a representação do sujeito colonial Bertha Mason, assim como as implicações entre o seu destino e o da personagem Jane Eyre. Essa discussão será provocada pelo diálogo com o ensaio "Três textos de mulheres e uma crítica do imperialismo" ["Three women's texts and a critique of imperialism"] de Gayatri Spivak. O ensaio, publicado pela primeira vez em 1985 (SPIVAK, 1986, p. $262-280)^{7}$, destaca-se pelo papel precursor que desempenhou ao ler o romance sob uma perspectiva pós-colonialista, assim como por questionar as leituras críticas feministas da década de 1970, que celebravam a trajetória da protagonista de Brontë como modelo de constituição do sujeito feminino individualista.

No seu ensaio, Spivak propõe-se a examinar as representações culturais do sujeito nativo à luz do que chama de "axiomática do imperialismo". (SPIVAK, 1995, p. 271) A escritora indiana começa o seu texto advertindo que qualquer leitura da ficção britânica do século dezenove é obrigada a considerar o projeto britânico do imperialismo. Spivak ratifica que o projeto imperia-

\footnotetext{
${ }^{4}$ Jane Eyre acompanha de forma detalhada o desenvolvimento (físico, moral, social, psicológico) da personagem Jane ao longo do tempo, desde a infância até a maturidade. Desta forma, o romance pode ser classificado também como um Bildungsroman, ou seja, um romance de formação.

5 Principalmente a partir da crítica feminista anglo-americana da década de 1970.

${ }^{6}$ Este enfoque tem por base a concepção de leitura contrapontual elaborada por Said em Cultura e imperialismo (1995), conforme veremos mais adiante neste trabalho.

${ }^{7}$ Spivak revisou e publicou o ensaio com modificações em 1999. (SPIVAK, 1999, p. 112 - 148) O texto citado neste trabalho é um recorte do primeiro, publicado em The post-colonial studies reader. (SPIVAK, 1995, p. 269 - 272), que contempla a parte que se refere a Jane Eyre e Vasto Mar de Sargaços e exclui a análise feita por Spivak do texto Frankenstein, de Mary Shelley.
} 
lista, levado à sociedade civil como a missão social da Inglaterra, consistiu em parte crucial da representação cultural da Inglaterra para os ingleses, e a literatura desempenhou um papel fundamental neste processo ${ }^{8}$. (cf. SPIVAK, 1995, p. 269)

A leitura de Spivak do romance Jane Eyre subverte ofoco da constituição da mulher individualista. Spivak contrapõe afigura de Jane Eyre à da nativa subalterna, Bertha Mason, que aparece dentro do discurso apenas como um significante, e excluída da norma vigente do individualismo. Nesse sentido, seu texto denuncia leituras do romance que apagam a individualidade de Bertha, como, por exemplo, aquelas que a consideram "apenas em termos psicológicos, como o duplo escuro de Jane” (SPIVAK, 1995, p. 271, tradução nossa) ${ }^{9}$.

Spivak defende queo individualismo feminista do século XIX extrapola o âmbito familiar, e inclui o projeto mais amplo da constituição do sujeito, parte da missão imperialista. Este projeto vai muito além da questão da reprodução sexual, envolvendo "o projeto de construção da alma" (SPIVAK, 1995, p. 271, tradução nossa) ${ }^{10}$ do sujeito colonial, considerado, pelo olhar europeu e para os fins imperialistas, como um ser não totalmente humano.A fala de um dos personagens de Brontë, o missionário St. John Rivers ${ }^{11}$, ilustra esse projeto de constituição do sujeito, ou "construção da alma”, implicado no imperialismo inglês:

Como abdicar? Essa é a minha vocação. Minha grande obra. Meus alicerces se firmam na terra para uma mansão no céu. Minhas esperanças de estar entre aqueles que renunciaram a todas as ambições pela glória de melhorar seus semelhantes, de levar o conhecimento ao reino da ignorância, de substituir a guerra pela paz, a servidão pela liberdade, a superstição pela religião, o medo do inferno pela esperança do paraíso. Devo abdicar disso? Isso me é mais precioso do que o sangue que corre em minhas veias. Isso é o que almejo e para o que vivo. (BRONTË, 2014, p. 640) ${ }^{12}$

A fala de St. John Rivers fundamenta o pressuposto de Spivak de que a barbárie do projeto imperialista é justificada pela noção de evolução e progresso da raça humana. Desta forma, através do projeto de construção da alma, “o 'sujeito' nativo é não exatamente um animal mas o objeto do que pode ser denominado o terrorismo do imperativo categórico... ." (SPIVAK, 1995, p. 271, tradução nossa) ${ }^{13}$ Tomando como exemplo a personagem caribenha de Jane Eyre, Spivak considera a caracterização de Bertha como um ser indeterminado, na fronteira entre o humano e o animal, como uma forma de legitimar a violação da sua humanidade. Por conseguinte, o projeto de construção de alma daquilo que nem pode ser considerado "Outro", pois não é visto como humano pelo europeu, é autorizado por um campo discursivo que extrapola os limites da lei humana, apontando para um ideal divino. As palavras do missionário St, John Rivers, "céu”, "paraíso", "religião", assim como sua lógica maniqueísta, atestam essa condição.

O argumento elaborado por Spivak apoia-se na ideia de que o imperialismo como missão

\footnotetext{
${ }^{8}$ Esse aspecto é explorado de forma contundente em Wide Sargasso Sea (1999), edição brasileira Vasto Mar de Sargaços (2012), de Jean Rhys, que reiteradamente e de diferentes maneiras, evidencia as implicações do projeto imperialista e das questões relacionadas à raça, gênero, nacionalidade e classe social. A escritora dominicana promove uma mudança radical de perspectiva, ao colocar Bertha, a personagem caribenha criada por Brontë, conhecida como "a louca do sótão", como protagonista do seu romance. Ao libertar a personagem "louca" do contexto do romance inglês, Rhys a ressignifica a partir de uma perspectiva pós-colonial.

9 "only in psychological terms, as Jane's dark double" (SPIVAK, 1995, p. 271).

10 "the project of soul making" (SPIVAK, 1995, p. 271).

${ }^{11}$ Este trecho foi citado por Spivak no seu segundo ensaio, no entanto optei por citar a partir das edições inglesa e brasileira que utilizo ao longo deste trabalho.

12 "Relinquish? What! my vocation? My great work? My foundation laid on earth for a mansion in heaven? My hopes of being numbered in the band who have merged all ambitions in the glorious one of bettering their race - of carrying knowledge into the realms of ignorance - of substituting peace for war - freedom for bondage - religion for superstition - the hope of heaven for the fear of hell? Must I relinquish that? It is dearer than the blood in my veins. It is what I have to look forward to, and to live for (BRONTË, 1999, p. 331).

13 ' [...] the native 'subject' is not almost an animal but rather the object of what might be termed the terrorism of the categorical imperative...."
} 
social cria um campo discursivo que dá sentido à trajetória de ascensão da protagonista Jane, que pode ser, então, deslocada da posição de anti-família, para o status de família legal, ao casar-se com Rochester. Considerando que o casamento da protagonista Jane Eyre só é possível graças à morte da primeira esposa de Rochester, a jamaicana Bertha Mason, Spivak denuncia que para que Janepossa se tornar a heroína feminista individualista da ficção britânica, é necessário que Bertha ponhafogo na casa e mate-se. A morte de Bertha é interpretada pela escritora indiana como uma alegoria do sujeito colonial que se autoimola para a glorificação do colonizador. (cf. SPIVAK, 1995, p. 271 - 272)

Os argumentos de Spivak são explorados por John Mc Leod(2010, p. $173-185)^{14}$ na sua leitura de Jane Eyre, que examina os contextos coloniais presentes no romance de Brontë, dentre eles, aquelerelacionado à economia colonial. Partindo do estudo realizado por Susan Meyer, em Imperialism at home: race and victorian women's fiction, Mc Leod ressalta a influência econômica do projeto imperialista no destino dos protagonistas. Ele destaca, por exemplo, que em Jane Eyre, a herança de vinte mil libras recebida pela protagonista, que sem dúvida contribui para assegurar o seu casamento com um homem da classe alta inglesa, é proveniente de um tio de Jane que trabalha na ilha da Madeira como agente de um produtor de vinho da Jamaica, envolvido com o tráfico de escravos. Além disso, a riqueza de Rochester é oriunda do dote de trinta mil libras que recebeu pelo seu casamento com a caribenha Bertha, uma vez que a lei inglesa o privou do direito à herança paterna por ser o filho caçula. Desta forma, a ascensão social da protagonista Jane, e o conforto material desfrutado pelos protagonistas só são possíveis graças à exploração econômica colonial.

Em última análise, pode-se dizer que a leitura realizada por Spivak é crucial não só por sublinhar o efeito determinante do projeto imperialista no romance vitoriano de Brontë, mas principalmente pelo foco naquilo que ela denominaa axiomática imperialista.Spivak insiste na maneira pela qual o projeto imperialista opera discursivamente, apontando o papel fundamental da criação de um campo discursivo legitimador deste projeto, que através da afirmação do seu conhecimento como verdade autorizada, torna-se capaz de exercer o seu domínio. Uma leitura contrapontual de Jane Eyre evidencia que o discurso autorizado de Rochester, sobre questões como diferenças culturais e nacionais, raça, gênero, sanidade, religião, etc., e o amparo que ele recebe da lei inglesa constituem os fatores legitimadores do seu domínio sobre Bertha. Esses discursos legitimados pela dominação colonial permitem que o jovem aventureiro inglês roube da sua esposa caribenha não só a sua riqueza material, mas o seu espírito, ao confiná-la como louca.

A relação entre a ficção britânica e o projeto imperialista também foi explorada por outros autores, com publicações posteriores ao texto de Spivak. Dentre eles, destacam-se a referência indispensável do livro Cultura e imperialismo de Edward Said (1995), lançado em 1993, e The empire writes back: theory and practice in post-colonial literature, deBill Ashcroft, Gareth Griffiths and Helen Tiffin (2002), publicado em 1989, e que consiste numa das principais articulações teóricas sobre a relação entre textos pós-coloniais e questões associadas à cultura pós-colonial. Os debates propostos por The empire writes back, através da variedade de textos abordada pelos autores, promovem uma revisão de concepções eurocêntricas sobre língua e literatura.

Para fins da discussão sobre a relação entre cultura britânica e o projeto imperial neste trabalho, é relevante destacar a concepção de leitura contrapontual elaborada por Said em Cultura e imperialismo (1995), a partir da abordagem que faz de Mansfield Park (1814) de Jane Austen. Said tem como ponto de partida a noção de contraponto da música clássica ocidental, em que "vários temas se opõem uns aos outros", resultando numa "polifonia" em que há "ordem e concerto, uma interação organizada que deriva dos temas, e não de um princípio melódico ou formal rigoroso externo à obra." (SAID, 1995, p. 87) De forma análoga, Said se dispõe a ler o modelo imperialista que molda os romances ingleses desagregando-o de qualquer princípio teórico geral baseado em códigos incorporadores, universalizantes e totalizantes, através de uma perspectiva con-

${ }^{14}$ John McLeod também dialoga com o ensaio de Spivak (1986).

https://periodicos.unifap.br/index.php/letras

Macapá, v. 9, n. 2, $2^{\circ}$ sem., 2019 
trapontual, que leva em consideração os comprometimentos locais, as sobreposições e interdependências entre o conjunto imperialista e os lugares periféricos que serviram como colônias.

Partindo da consideração de que o imperialismo é um processo que ocorre como parte da cultura metropolitana, Said propõe-se a relê-lo "não de forma unívoca, mas em contraponto", ou seja, "com a consciência simultânea da história metropolitana que está sendo narrada e daquelas outras histórias contra (e junto com) as quais atua o discurso dominante." (SAID, 1995, p. 87) Desta forma, ele aponta a maneira pela qual o modelo imperialista é desmontado nos romances ingleses através da história específica da colonização, da resistência e do nacionalismo nativo. Por conseguinte, Said alega que identidades culturais antes concebidas "como essências concedidas pela divindade" passam a ser vistas como "conjuntos contrapontuais", uma vez que "nenhuma identidade pode existir por si só, sem um leque de opostos, oposições e negativas" (SAID, 1995, p. 88), uma noção de identidade que encontra ressonância nas elaborações do escritor e filósofo martinicano Glissant (2010) sobre o pensamento rizomático e na sua Poética da Relação. Neste sentido, o estudo da anglicidade, por exemplo, considerado de forma contrapontual, pode ser analisado como produto da colaboração entre a história africana e o estudo da África na Inglaterra (cf. SAID, 1995, p. 88).

Por esta perspectiva, Said determina que é possível estabelecer um contraponto entre "padrões explícitos dos textos ingleses sobre a Inglaterra e representações do mundo além das ilhas britânicas.” (SAID, 1995, p. 122). De forma significativa para fins deste trabalho, Said alega que "a modalidade intrínseca desse contraponto não é temporal, e sim espacial." No contexto geográfico da luta das metrópoles europeias pelos impérios, Said reivindica a atenção às questões geográfico-espaciais, observando que, herdeiros que somos do legado de Proust e Lukács, "ficamos tão acostumados a pensar que o enredo e a estrutura do romance são constituídos sobretudo pela temporalidade que temos descurado da função do espaço, da geografia e da localização". (SAID, 1995, p. 125) Entretanto, é através da atenção dada pela sua abordagem a estas questões que Said consegue identificar como os fundamentos da expansão imperialistas estão envolvidos, muitas vezes de forma subliminar, em romances pré-imperialistas como Mansfield Park. Ao percorrer este romance, por exemplo, Said identifica a maneira como em Mansfield Park as realidades do poderio britânico no ultramar encontram correspondência nos arranjos domésticos da propriedade Bertram, através da análise daquilo que ele chama de "estrutura de atitudes e referências". (SAID, 1995, p. 137) Conforme explica, a expressão refere-se a uma "topografia cultural distinta" que revela como "as estruturas de localização e referência geográfica aparecem nas linguagens culturais da literatura, história ou etnografia”. (SAID, 1995, p. 88) Este aspecto, segundo ele, une várias obras individuais que, a não ser por essas estruturas, muitas vezes aludidas de forma bastante sutil, não possuem qualquer outro vinculo entre elas, nem com o que ele chama de "uma ideologia oficial do 'império"'. (SAID, 1995, p. 88)

Duas questões relevantes são destacadas por Said na análise minuciosa que faz do romance Mansfield Park. Uma é a conexão entre o que a personagem Fanny faz "como um movimento doméstico ou em pequena escala no espaço" e "os movimentos mais amplos, mais abertamente coloniais de sir Thomas", como dois movimentos interdependentes (SAID, 1995, p. 130). Esta relação demonstra, segundo Said, a maneira como Austen considera a importância de um império para a situação doméstica no romance. A outra questão é o significado de Antígua em Mansfield Park, a colônia inglesa na qual sir Thomas possui fazendas de cana-de-acúcar, fonte da sua riqueza. A pergunta proposta por Said é "por que Austen escolhe Antígua para fundar a riqueza do sir Thomas?" (SAID, 1995, p. 130 - 131) Said conclui que, ao ler o romance, fica evidente a ideia de que "por mais isolado e ilhado que fosse o local inglês (por exemplo, Mansfield Park), ele requer um sustento ultramarino. A propriedade de sir Thomas no Caribe teria que ser uma fazenda de cana com trabalho escravo (abolido apenas na década de 1830)", fato que Austen tinha plena consciência, conforme asseverado por Said (1995, p. 131). A riqueza advinda de Antígua, portanto, é aquilo que proporciona as "melhorias domésticas" para os personagens de Mansfield Park 
(SAID, 1995, p. 135) e que, segundo observa Said, "aos olhos de Austen se converte em propriedade, em ordem e, no final do romance, em conforto, como um bem adicional". (SAID, 1995, p. 132)

A leitura contrapontual realizada por Said de textos literários canônicos, como a de Mansfield Park, amplia a discussão proposta por Spivak acerca do romance Jane Eyre, revelando a complexidade e o aspecto multifacetado, e ao mesmo tempo delicado, da relação entre cultura e imperialismo. Nesse sentido, a articulação contrapontual é valiosa para a abordagem da ligação entre o romance Jane Eyre e sua implicação no projeto imperialista, que, conforme defendido por Spivak, aparece no romance como missão social da Inglaterra, e também como parte crucial da representação cultural da Inglaterra para os ingleses (cf. SPIVAK, 1995, p. 269).

A abordagem de Spivak sobre o papel fundamental desempenhado pela missão colonizadora em Jane Eyre encontra ressonância nas elaborações de Said, que procura evidenciar a forma como o espaço socialmente autorizado e desejável na Inglaterra ou Europa metropolitana está intimamente associado aos mundos periféricos a eles subordinados, definindo as atitudes sobre "o domínio, o controle, o lucro, a ascensão e as conveniências - que crescem com uma força assombrosa do século XVII ao final do século XIX”. (SAID, 1995, p. 88) Said reivindica que as estruturas identificadas por ele nos textos literários analisados "estão ligadas ao desenvolvimento da identidade cultural britânica, como essa identidade imagina a si mesma num mundo concebido em termos geográficos". Esse aspecto será explorado mais adiante, quando serão discutidos os espaços subalternos do sujeito colonial no romance Jane Eyre. No romance vitoriano de Charlotte Bronte, os espaços ocupados pelos sujeitos coloniais são definidos pelas ideias a respeito das raças e territórios dependentes, por questões sutis da avaliação moral, e em última análise, pela "estrutura de atitudes e referências" (SAID, 1995, p. 88), conforme articulada por Said.

Um dos aspectos que chamam a atenção do leitor de Jane Eyre é que os espaços do império britânico e os espaços coloniais são incomunicáveis, separados por um vasto e incomensurável vão. Esse mundo, marcado pela fissura, é apresentado como um mundo dividido pela lógica binária da história imperial, ou seja, por um discurso maniqueísta ${ }^{15}$, que demoniza o Outro cultural e, sob a justificativa da suposta nobreza da missão colonizadora, classifica o mundo entre bons e maus, superiores e inferiores, civilizados e selvagens ${ }^{16}$.

Uma leitura atenta da caracterização dos espaços coloniais em Jane Eyre torna evidente a concepção imperial de espaço (história) como um palco, em que é dramatizado o tema universal da imposição de uma ordem, a "ordem" eurocêntrica, diante da dimensão considerada "caótica" do mundo colonial. Conforme observado por Paul Carter (1995)no seu ensaio "Spatial history" ["História espacial"], a história imperial elimina o mundo dos sujeitos históricos e das escolhas espaciais, erigindo, meio à multiplicidade inapreensível da experiência histórica, uma história única, que tem como pretensão instaurar a ordem no caos. (cf. CARTER, 1995, p.376)

Num ponto crucial do romance Jane Eyre, Rochester reporta a Jane o momento da sua decisão de deixar o Caribe, voltar para a Europa, e manter confinada, na sua propriedade na Inglaterra, a esposa jamaicana, declarada louca pela autoridade médica inglesa. Essa parte da narrativa é decisiva, não só pela caracterização do espaço colonial como espaço caótico e maligno, mas também por revelar o processo de legitimação da constituição do espaço marginal ocupado pelo sujeito colonial Bertha Mason. Vale a pena fazer uma leitura mais atenta dessas passagens:

Certa noite fui acordado pelos gritos dela. É claro que desde que os médicos diagnosticaram sua loucura, eu a mantive em cativeiro. Pois bem, era uma daquelas noites abrasadoras do Caribe que precedem os furacões daquelas partes. Como não conseguia dormir, resolvi levantar-me e abrir a

\footnotetext{
15 McLeod (2010, p. 180) também endossa a ideia de que Jane Eyre caracteriza-se pela presença marcada do discurso maniqueísta colonial, segundo o qual a realidade é concebida em termos de polaridades, derivadas das oposições entre bom e mal, luz e escuridão, por exemplo.

${ }^{16}$ Esse aspecto é evidenciado através da fala do missionário St. John Rivers, citada anteriormente.
} 
janela. O ar estava semelhante ao vapor de enxofre, e eu não conseguia refrescar-me. Os mosquitos zumbiam com mal humor em volta do quarto. De onde estava eu podia ver o mar que bramia como se fosse um maremoto. Sobre eles, nuvens negras se formavam. A lua grande e avermelhada estava pondo-se sobre as ondas. Ela lançava o seu olhar sangrento por sobre um mundo que tremia com a agitação da tempestade, como uma bala de canhão. Eu estava fisicamente influenciado pela atmosfera e por aquela cena. Meus ouvidos se encheram das maldições que a louca ainda gritava, e às quais misturava o meu nome com um tom de raiva demoníaca e com um linguajar e tanto! Nem mesmo uma meretriz assumida jamais teve um vocabulário tão sujo como o dela. Apesar de separados por dois quartos, eu ouvia cada uma de suas palavras. As paredes finas das casas do Caribe não opunham qualquer obstáculo aos seus gritos de loba. (BRONTË, 2014, p. $531-532)^{17}$

No excerto acima, é curioso notar que apesar de boa parte do parágrafo ser dedicada à descrição minuciosa do espaço colonial, ele começa e termina com os gritos da esposa caribenha de Rochester. Desta forma, a caracterização da Jamaica por Rochester oferece uma espécie de explicação para a natureza demoníaca e animalesca de Bertha. A natureza da ilha confunde-se com a natureza da sua esposa, e ambas parte de um mundo prestes a entrar em ebulição, uma ameaça à integridade física e mental do protagonista inglês. A crença de que a atmosfera do lugar exerce uma influência sobre o caráter e a personalidade dos seus habitantes é reiterada quando o próprio Rochester declara que "estava fisicamente influenciado pela atmosfera e por aquela cena." O comentário é justaposto ao seu sentimento de desespero diante da ameaça de perda da sua identidade, aqui simbolizada pelo seu próprio nome, apropriado por Bertha e "misturado" aos seus gritos animalescos e seu vocabulário inferior.

O mundo caribenho é, então, descrito por Rochester como um inferno na terra, um lugar inóspito e sufocante, infestado por mosquitos e dominado pela selvageria que, assim como a natureza indomável da sua esposa, ameaça contaminá-lo, roubando-lhe o seu espírito livre e cultivado de homem europeu. Em contraponto à descrição dantesca do espaço da ilha caribenha, a Europa é caracterizada por Rochester como o símbolo da riqueza material e espiritual, da sabedoria e da liberdade, em última análise, das conquistas e do aprimoramento humano. O discurso maniqueísta de Rochester é evidenciado quando o protagonista descreve a sua saída do Caribe e a volta para a Europa como a saída do "inferno" para "a casa de Deus", ao declarar, "Esta vida é um inferno [...] Tenho o direito de sair daqui se puder [...] Deixe que eu me livre disto tudo, e volte para a casa de Deus!" (BRONTË, 2014, p. 532) ${ }^{18}$ Rochester apropria-se do discurso religioso para legitimar as suas ações. Assim, seu livre arbítrio é amparado por uma espécie de justiça divina que permite que ele aja à revelia da lei humana.

A Europa, como espaço relacional, significa uma espécie de ordem restauradora para o caos e a selvageria que caracterizam o mundo caribenho descrito pelo protagonista ${ }^{19}$. Este aspecto é posto em evidência quando lemos que aquilo que recompõe o ânimo e a razão do protagonista, devastado pela atmosfera infernal da noite caribenha é "um vento fresco vindo da Europa"

\footnotetext{
17 One night I had been awakened by her yells - (since the medical men had pronounced her mad, she had, of course, been shut up) - it was a fiery West Indian night; one of the description that frequently precede hurricanes of those climates. Being unable to sleep in bed, I got up and opened the window. The air was like sulphur-steams - I could find no refreshment anywhere. Mosquitoes came buzzing in and hummed sullenly round the room; the sea, which I could hear from thence, rumbled dull like an earthquake - black clouds were casting up over it; the moon was setting in the waves, broad and red, like a hot cannon-ball - she threw her last bloody glance over a world quivering with the ferment of tempest. I was physically influenced by the atmosphere and scene, and my ears were filled with the curses the maniac still shrieked out; wherein she momentarily mingled my name with such a tone of demon-hate, with such language! - no professed harlot ever had a fouler vocabulary than she: though two rooms off, I heard every word - the thin partitions of the West India house opposing but slight obstruction to her wolfish cries. (BRONTË, 1999, p. 271 - 272)

18 "This life [...] is hell [...] I have a right to deliver myself from it if I can [...] let me break away, and go home to God!” (BRONTË, 1999, p. 272)

19 Tanto Spivak (1986) quanto McLeod (2010) chamam a atenção para a representação da Jamaica no romance de Brontë, destacando a caracterização da ilha, pelo protagonista Rochester de Jane Eyre, como um lugar infernal, e contrapondo este espaço à função restauradora do mundo europeu.
} 
(BRONTË, 2014, p. 533) ${ }^{20}$, trazendo consigo “a verdadeira sabedoria que me consolou naquela hora e me mostrou o caminho certo a seguir.” (BRONTË, 2014, p. 533) ${ }^{21}$ É curioso notar que também o espaço físico do Caribe, não só o espírito de Rochester, é restaurado pela influência europeia. Os ventos europeus devolvem o oxigênio e a vida à paisagem estagnada do Caribe:

O vento doce da Europa continuava a sussurrar sobre folhas revigoradas, e o Atlântico trovejava em liberdade gloriosa. Meu coração, que havia muito tempo estava seco e queimado, se encheu de vigor e de sangue renovado. Meu ser ansiava por renascimento, minha alma estava sedenta por um gole de água fresca. Vi a esperança reviver e senti a possibilidade de regeneração. De uma arcada florida no fundo do meu jardim contemplei o mar, mais azul do que o céu. Além dele lá estava o Velho Mundo. Era lá que as perspectivas se abriam para mim (BRONTË, 2014, p. 533). ${ }^{22}$

O discurso de Rochester não só demoniza a alteridade do lugar, como apaga a(s) história(s) e a humanidade dos sujeitos coloniais, fundando umahistória única, que instaura uma ordem no "caos". A ordem e o progresso europeus são traduzidos, no discurso ao mesmo tempo positivista e religioso do personagem, pelos anseios de liberdade, esperança e evolução. Assim, as palavras "renascimento" e "regeneração", no excerto acima, não só sugerem as oposições entre as supostas trevas da ignorância do mundo colonial e as luzes da razão do mundo europeu, como também marcam a saída do inferno e o retorno à casa de Deus. Desta forma, quando Rochester reporta a Jane o momento em que é tomado pela vontade de retornar para a Inglaterra, é como se ele ouvisse um chamado da própria Esperança, com "e" maiúsculo, personificada. Esse arranjo discursivo confere ao protagonista uma espécie de licença divina para agir conforme a sua vontade e acima da lei. Por conseguinte, apesar de legalmente casado com Bertha, é possível observaro imperativo para um deslocamento para além da lei, que permite que ele se livre da esposa, como quem se livra do próprio demônio:

\begin{abstract}
"Vá"- disse a Esperança. - "Volte a viver na Europa. [...] Pode levar a louca consigo para a Inglaterra. Encerre-a em Thornfield com a atenção e as precauções adequadas. E viaje para onde tiver vontade e forme os novos laços que quiser. Aquela mulher que abusou tanto do seu sofrimento e que sujou tanto o seu nome, ultrajou sua honra e arruinou sua juventude, não é a sua esposa nem você é seu marido. Que esteja cercada dos cuidados que sua doença requer, e terá você feito tudo o que Deus e a humanidade exigem. Que a identidade dela e as ligações dela com você sejam sepultadas no esquecimento. [...]" (BRONTË, 2014, p. 533 - 534) ${ }^{23}$
\end{abstract}

Amparado por "Deus e a humanidade", Rochester não só "[sepulta] no esquecimento" a sua ligação com Bertha, ficando livre para casar-se à revelia da lei, mas, significativamente, sepulta também a identidade da esposa no esquecimento.

Aquilo que permite que a identidade de Bertha seja sepultada é, em primeiro lugar, o discurso legitimado dos médicos ingleses que decretaram a sua loucura, autorizando e tornando "na-

20 "A wind fresh from Europe". (BRONTË, 1999, p. 272)

21 " $[\ldots]$ it was true Wisdom that consoled me in that hour, and showed me the right path to follow." (BRONTË, 1999 , p. 272)

22 "The sweet wind from Europe was still whispering in the refreshed leaves, and the Atlantic was thundring in glorious liberty; my heart, dried up and scorched for a long time, swelled to the tone, and filled with living blood - my being longed for renewal - my soul thirsted for a pure draught. I saw hope revive - and felt regeneration possible. From a flowery arch at the bottom of my garden I gazed over the sea - bluer than the sky: the old world was beyond; clear prospects opened thus [...].” (BRONTË, 1999, p. 272)

23 "'Go', said Hope, 'and live again in Europe [...]. You may take the maniac with you to England; confine her with due attendance and precautions at Thornfield: than travel yourself to what clime you will, and form what new tie you like. That woman, who has so abused your long-suffering, so sullied your name, so outraged your honour, so blighted your youth, is not your wife, nor are you her husband. See that she is cared foras her condition demands, and you have done all that God and humanity require of you. Let her identity, her connection with yourself, be buried in oblivon [...].”" (BRONTË, 1999, p. 272 - 273) 
tural", portanto, o ato de Rochester de confiná-la. Na primeira passagem de Jane Eyre citada nesta seção, em que Rochester descreve a paisagem infernal da noite caribenha, é curioso notar que o seu comentário, "É claro que desde que os médicos diagnosticaram sua loucura, eu a mantive em cativeiro" (BRONTË, 2014, 531), segue uma lógica tão "natural" que aparece de forma incidental no texto, entre parênteses na edição inglesa: ("since the medical men had pronounced her mad, she had, of course, been shut up") (BRONTË, 1999, p. 272 - 273). É válido observar, no entanto, que o comentário é justaposto à descrição dos gritos de Bertha, sugerindo não só que esses gritos demoníacos durante a noite começaram após o seu confinamento, mas também que a "loucura" de Bertha é causada pelo confinamento e não o contrário. Atestados de loucura ou lucidez são as armas usadas pelo aventureiro inglês para garantir o controle sobre Bertha, e assegurar a fortuna que herdou do seu casamento com ela. A arbitrariedade em relação ao "diagnóstico" de Bertha é também evidenciada pela observação de Rochester de que "[Bertha] tinha intervalos de lucidez que duravam dias. Às vezes até semanas, durante os quais não dispensava abusos à minha pessoa.” (BRONTË, 2014, p. $534)^{24}$

Bertha, cuja identidade foi, declaradamente no texto de Brontë, sepultada no esquecimento, ocupa, de diferentes maneiras, uma espécie de não-lugar ${ }^{25}$ no romance vitoriano de Charlotte Brontë.Significativamente, o espaço físico onde Bertha vive na propriedade de Rochester na Inglaterra, secretamente confinada por seu marido, e vigiada vinte e quatro horas por dia pela empregada Grace Poole, é um quarto sem janela (cf. BRONTË, 2014, p. 507) situado no sótão de Thornfield Hall. O esconderijo de Bertha fica dentro de outro quarto maior, e a sua porta de entrada, encoberta por tapetes, fica escondida. (cf. BRONTË, 2014, p. 366) A respeito do espaço destinado ao longo confinamento de Bertha, Rochester comenta: "Fiquei aliviado quando finalmente pude colocá-la em Thornfield e alojá-la naquele quarto do terceiro andar que ela transformou nestes dez anos no covil de um animal selvagem ou numa cela de duende." (BRONTË, 2014, p. 534$)^{26}$

Além de ocupar fisicamente uma espécie de não-lugar em Thornfield e na sociedade inglesa, é relevante notar que Bertha não tem voz no texto vitoriano, literalmente, pois não fala, apenas emite sons perturbadores, na visão da personagem Jane Eyre. Além disso, a natureza animalesca da personagem caribenha de Brontë é reiteradamente salientada pela fala impositiva da narradora Jane. Esse aspecto pode ser ilustrado pelo episódio em que Bertha, no meio da noite, ataca e deixa ferido o seu irmão, Richard Mason. Jane, que na ocasião ainda ignora a existência da primeira esposa de Rochester, descreve os gritos que ouve como se fossem os rugidos de um animal: "A noite, seu silêncio e sua quietude e tudo o mais foi rasgado por um som selvagem, agudo e estridente que percorreu Thornfield Hall de ponta a ponta."(BRONTË, 2014, p. 361) ${ }^{27}$ Logo em seguida, Jane comenta: "A coisa que se expressara com tamanha fúria teria de se recuperar antes que pudesse repetir o esforço.” (BRONTË, 2014, p. 362, grifo nosso) ${ }^{28}$

Outras referências feitas pela protagonista à misteriosa criatura comparam-na a um "de-

\footnotetext{
24 "she had lucid intervals of days - sometimes weeks - which she filled up with abuse of me (BRONTË, 1999, p. 273).

25 O termo não-lugar foi cunhado por Marc Augé (1997) ao realizar uma espécie de antropologia da sobremodernidade. O sentido do termo no contexto desse trabalho difere daquele abordado pelo autor, que introduz o conceito de não-lugares para se referir a lugares transitórios da sobremodernidade. Entretanto, utilizo o termo para recuperar a ideia elaborada por Augé (1997, p. 169) de que "o lugar é triplamente simbólico: ele simboliza a relação de cada um de seus ocupantes consigo mesmo, com os outros ocupantes e com a história comum". Desse modo, "nãolugar" é um espaço no qual nem a identidade, nem a relação e nem a história sejam simbolizados, ideia que ganha ressonância neste trabalho.

${ }^{26}$ Glad was I when I at last got her to Thornfield, and saw her safely lodged in that third-storey room, of whose secret cabinet she has now for ten years made a wild beast's den - a goblin's cell (BRONTË, 1999, p. 273).

27 "The night - its silence - its rest, was rent in twain by a savage, a sharp, a shrilly sound that ran from end to end of Thornfield Hall” (BRONTË, 1999, p. 183)

28 “The thing delivering such utterance must rest before it could repeat the effort" (BRONTË, 1999, p. 183)
} 
mônio zombeteiro" ou ainda a uma "ave de rapina sequiosa por carniça".(BRONTË, 2014 , p. 369 ${ }^{29}$ Em diversos momentos, ambos os protagonistas do romance realista inglês aproximam Bertha de um monstro, enfatizando reiteradamente e por diversas comparações, a sua natureza violenta, selvagem e demoníaca. A relação entre confinamento e a ideia de monstruosidade atribuída ao indivíduo é elaborada por Foucault (2014) em

Vigiar e punir: nascimento da prisão. No primeiro capítulo da segunda parte deste volume, Foucault trata da temática da transição das formas de punição na passagem do século XVIII para o XIX, quando a noção de cidadania e a consciência de direitos humanos ganham evidência. Nesse momento, Foucault destaca que a punição deixa de ser através da tortura ao corpo e passa a ser o isolamento do indivíduo. Diante desse cenário, Foucault elabora a maneira como a "imagem do monstro 'vomitado' pela natureza” (FOUCAULT, 2014, p. 90) confere legitimidade para o seu isolamento com a finalidade de proteger o resto do corpo social:

Constitui-se assim um formidável direito de punir, pois o infrator torna-se o inimigo comum. Até mesmo pior que um inimigo, é um traidor pois ele desfere seus golpes dentro da sociedade. Um "monstro". Sobre ele, como não teria a sociedade um direito absoluto? Como deixaria ela de pedir sua supressão pura e simples? E se é verdade que o princípio dos castigos deve estar subscrito no pacto, não é necessário, logicamente, que cada cidadão aceite a pena extrema para aqueles dentre eles que os atacam como organização? (FOUCAULT, 2014, p. 89)

É relevante notar que a "monstrosidade" de Bertha em Jane Eyre relaciona-se a sua condição de mulher crioula e mestiça. De fato, diversas passagens do romance de Brontë endossam que a caracterização de Bertha como uma espécie de não-pessoa, desprovida de individualidade, mais assemelhada a uma besta selvagem do que a um ser humano, aparece indissociável da questão racial $^{30}$. As descrições físicas da personagem caribenha, tanto por Jane quanto por Rochester, confirmam essa associação. A primeira vez que Jane vê Bertha, no episódio em que a primeira esposa Rochester rasga o véu de noiva de Jane, ela pensa ter visto um ser de outro mundo, um fantasma ou um vampiro. Curiosamente, o aspecto ao mesmo tempo selvagem e sobrenatural de Bertha está relacionado aos seus traços mulatos, conforme evidencia a descrição da sua cor e sua fisionomia, no diálogo entre Rochester e Jane, que ocorre logo após a "aparição" de Bertha para a protagonista:

- Você viu o seu rosto?

- [...] vi perfeitamente o reflexo do seu rosto e dos seus traços no espelho escuro e quadrangular.

- E como eram eles?

- Eram medonhos e assustadores para mim. Oh, senhor, jamais vira um rosto como aquele! Era um rosto sem cor, um rosto selvagem. Quem me dera poder esquecer seus olhos vermelhos e terríveis e suas feições sombrias e arrogantes.

- Os fantasmas em geral são pálidos.

- Senhor, esse era cor de púrpura. Os lábios eram grossos e escuros [...] (BRONTË, 2014, p. 491) 31

A cor escura de Bertha é referida por Rochester em outras passagens, que também evidenciam a associação entre a monstruosidade, ou a "coisificação", e a questão racial: "Quando lembro que aquela coisa que voou na minha garganta esta manhã poderia ter colocado seu rosto

\footnotetext{
29 "mocking demon", “carrion-seeking bird of prey"(BRONTË, 1999, p. 185).

${ }^{30}$ Este aspecto também é abordado por John Mc Leod (2012, p. 177).

31 "Did you see her face?"

"[...] I saw the reflection of the visage and features quite distinctly in the dark oblong glass"

"And how were they?"

"Fearful and ghastly to me - oh, sir, I never saw a face like it! It was a discoloured face - it was a savage face. I wish I could forget the roll of the red eyes and the fearful blackened inflation of the lineaments!"

"Ghosts are usually pale, Jane."

"This, sir, was purple: the lips were swelled and dark [...]” (BRONTË, 1999, p. 250)
} 
negro e escarlate sobre o ninho da minha pombinha, meu sangue coagula." (BRONTË, 2014, p. 535, grifo nosso) $)^{32}$ Em outra passagem reveladora, Rochester fala a Jane sobre sua busca pela mulher ideal: "Esperava encontrar alguém que me completasse. O oposto da mestiça." (BRONTË, 2014, p. 537) ${ }^{33}$ Logo depois, imbricada à questão racial, ele declara que o principal atributo de sua esposa, o que lhe causa mais desgosto, é a devassidão, a inclinação para a orgia e os vícios (cf. BRONTË, 2014, p. 537). Essas descrições corroboram a hipótese, bastante difundida em discursos coloniais, de que indivíduos mestiços são seres degenerados e animalescos. Fica evidente, no romance vitoriano, que a raça de Bertha e a sua origem caribenha ratificam e fundamentam não só a sua bestialidade, como também a sua insanidade.

Entretanto, é curioso que as descrições de Bertha sejam tão contraditórias. A contradição deve-se principalmente ao comentário de Rochester de que quando a conheceu, a beleza de Bertha era motivo de orgulho em Spanish Town. O próprio Rochester confirma que viu em Bertha uma mulher bela e atraente: "Eu a achei uma linda mulher, parecida até com Blanche Ingram. Alta, morena e majestosa" (BRONTË, 2014, p. 528) ${ }^{34}$, e confessa que havia ficado enfeitiçado pelos encantos e habilidades que a jovem jamaicana exibia. É válido notar também que, no arranjo do casamento, o valor de troca de Rochester está pautado na sua superioridade racial: "Sua família, assim como ela própria, queria segurar-me porque eu era de boa linhagem." (BRONTË, 2014, p. 528) ${ }^{35}$ No entanto, Rochester declara não saber do dote de Bertha, seu valor de troca, e que se casou, não por razões financeiras, mas porque estava deslumbrado e embriagado pela beleza da jamaicana e extasiado pelos sentidos. É interessante também o seu comentário para Jane de que o casamento foi realizado em pouco tempo, "antes mesmo que eu pudesse localizar-se no tempo e no espaço" (BRONTË, 2014, p. 528) ${ }^{36}$, como se ele estivesse contaminado pela atmosfera tóxica do Caribe, sem controle das suas faculdades mentais.

Outro aspecto que chama a atenção em Jane Eyre é a indeterminação em relação às descrições de Bertha feitas pela protagonista Jane. Conforme visto anteriormente, na primeira visão que Jane tem de Bertha, ela é comparada a uma aparição, um vampiro, um fantasma, um vulto (cf. BRONTË, 2014, p. 491-492). A primeira imagem do rosto da mulher misteriosa para Jane, é a do seu reflexo num espelho escuro:"vi perfeitamente o reflexo do seu rosto e dos seus traços no espelho escuro e quadrangular.”(BRONTË, 2014, p. 491) ${ }^{37}$. Chama ainda mais atenção o fato de que, ainda que a imagem de Bertha tenha sido vislumbrada apenas como um reflexo num espelho escuro, Jane assevera que a viu "perfeitamente", "com distinção" na versão inglesa. A descrição feita pela jovem Jane, quando Rochester a leva para conhecer a esposa caribenha, também confirma a indeterminação da caracterização de Bertha:

\begin{abstract}
$\mathrm{Na}$ escuridão, numa das extremidades do quarto, um vulto corria de um lado para o outro. Não era possível dizer à primeira vista se era uma fera ou um ser humano. Tinha-se a impressão de que se arrastava de quatro. Ameaçava morder e rosnava como um estranho animal selvagem. Mas estava coberto por roupas e uma quantidade imensa de cabelo escuro com mechas cinzentas, selvagem como uma juba, encobrindo sua cabeça e seu rosto. (BRONTË, 2014, p. 507) ) $^{38}$
\end{abstract}

\footnotetext{
32 "When I think of the thing which flew at my throat this morning, hanging its black and scarlet visage over the nest of my dove, my blood curdles". (BRONTË, 1999, p. 273)

33 "I longed only for what suited me - for the antipodes of the Creole". (BRONTË, 1999, p. 274)

34 "I found her a fine woman, in the style of Blanche Ingram: tall, dark and majestic" (BRONTË, 1999, p. 269).

$35^{\prime \prime} H e r$ family wished to secure me because I was of a good race; and so did she” (BRONTË, 1999, p. 269).

36 “[...] almost before I knew where I was" (BRONTË, 1999, p. 269).

37 "I saw the reflection of the visage and features quite distinctly in the dark oblong glass" (BRONTË, 1999, p. 258)

${ }^{38}$ In the deep shade, at the farther end of the room, a figure ran backwards and forwards. What is was, whether beast or human being, one could not, at first sight, tell: it grovelled, seemingly, on all fours; it snatched and growled like some strange wild animal: but it was covered with clothing, and a quantity of dark, grizzled hair, wild as a mane, hid its head and face. (BRONTË, 1999, p. 258)
} 
Nota-se, no excerto acima, que todas as frases que descrevem a figura de Bertha são vagas e incertas. Essa imprecisão é lida por McLeod como uma evidência de como os discursos coloniais fracassam em representar adequadamente o sujeito colonial (cf. McLEOD, 2010, p. 184). Além disso, a passagem acima revela o esforço de Jane em descrever algo que escapa à representação, uma vez que a figura de Bertha permanece indefinível, seja pelo movimento de correr de um lado para o outro, pela escuridão ou pelo rosto encoberto. McLeod também interpreta a imprecisão da descrição de Bertha na narrativa de Jane como um momento de crise num romance realista, que "é empurrado para os seus limites pela presença de um sujeito colonizado rebelde que ameaça escapar aquilo que o sentencia" (McLEOD, 2010, p. 185, tradução nossa) $)^{39}$. Por isso, ele sugere que "Talvez neste momento Jane Eyre seja mais um texto pós-colonial do que colonial"'(McLEOD, 2010, p. 185, tradução nossa) ${ }^{40}$.

$\mathrm{Na}$ abordagem realizada por este trabalho, que se propõe a fazer uma leitura contrapontual do romance tendo como foco o projeto imperialista,é fundamental considerar a imbricação entre identidade e questões como raça, nacionalidade, classe e gênero. Essas relações colocam em primeiro plano o contexto colonial do romance e os fatores que determinaram a complexa condição de exílio da personagem caribenha Bertha Mason e a ascensão do casal protagonista. O apagamento da identidade de Bertha, declarado como um ato intencional por Rochester (BRONTË, 1999 , p. 272 - 273), e a posição que a personagem ocupa, física e simbolicamente, evidenciam que não há espaço para uma mulher crioula e mestiça na sociedade vitoriana inglesa. Por outro lado, o enfoque no projeto imperialista, a partir de uma leitura contrapontual do romance, evidencia que não há como dissociar a trajetória de progresso da heroína individualista da ficção britânica, Jane Eyre, da morte física, simbólica e espiritual do sujeito colonial feminino Bertha Mason. O lugar de prestígio ocupado pelo casal Rochester e Jane Eyre na sociedade inglesa e no romance do século XIX corrobora a ideia de que o sujeito colonial deve ser sacrificado para a glorificação do colonizador.

\section{Referências}

ASHCROFT, B; GRIFFITHS, G.; TIFFIN, H. The empire writes back: theory and practice in postcolonial literatures. 2. ed. London/New York: Routledge, 2002.

AUGÉ, M. Não-lugares: introdução a uma antropologia da supermodernidade. Trad. Maria Lúcia Pereira. Campinas, SP: Papirus, 1994. (Coleção Travessia do Século)

BRONTË, C. Jane Eyre. Introd. Sally Minogue. London: Wordsworth Classics, 1999.

BRONTË, C. Jane Eyre. Trad. Carlos Duarte e Anna Duarte. São Paulo: Martin Claret, 2014.

CARTER, P. Spatial history. In: ASHCROFT, B.; GRIFFITHS, G.; TIFFIN, H. (Org.). The postcolonial studies reader. London and New York: Routledge, 1995, p. 375-377.

De FREITAS, V. O espaço rizomático de Vasto Mar de Sargaços de Jean Rhys. Babel Revista Eletrônica de Linguas e Literaturas Estrangeiras (DEDC II - UNEB), Alagoinhas, v. 4, n. 2, p. 26-40, ago./dez. 2014.

De FREITAS, V. Cartografias do exilio: errância e espacialidade na ficção da escritora caribenha Jean Rhys. 2017. 280 f. Tese (Doiutorado em Letras) - Instituto de Letras, Universidade Federal da Bahia, Salvador, 2017. Disponível em: < https://repositorio.ufba.br/ri/handle/ri/26665>. Acesso em: 4 ago. 2019.

FOUCAULT, M.Vigiar e punir: nascimento da prisão. Trad. Raquel Ramalhete. 40 ed. Petrópolis, RJ: Vozes, 2014.

GLISSANT, E. Poetics of relation. Trad. Betsy Wing. Ann Arbor: University of Michigan Press, 2010.

\footnotetext{
39 "[...] is pushed to its limits by the presence of an unruly colonised subject who threatens to escape that which sentences her". (McLEOD, 2010, p. 185)

40 "Maybe at this moment Jane Eyre is more a postcolonial than colonial text". (McLEOD, 2010, p. 185)
} 
McLEOD, J. Beginning postcolonialism. 2. ed. Manchester: Manchester University Press, 2010.

MINOGUE, S. Introduction. In: BRONTË, Charlotte. Jane Eyre. Introd. Sally Minogue. London: Wordsworth Classics, 1999, p. V - XXIII.

RHYS, J. Wide Sargasso Sea. Notas e introd. Angela Smith. London: Penguin, 1997.

RHYS, J. Vasto Mar de Sargaços. Trad. Léa Viveiros de Castro. Introdução: Carla Pontílio.

Rio de Janeiro: Rocco, 2012.

SAID, E. Cultura e imperialismo.Trad. Denise Bottman. São Paulo: Cia das Letras, 1995.

SPIVAK, G C. Three women's texts and a critique of imperialism. Critical Inquiry, Chicago, v. 12, n. 1, p. 243-261, autumn 1985.

SPIVAK, G. C. Three women's texts and a critique of imperialism. In: GATES JR, H. L.; AP-

PIAH, A. (Ed.) 'Race', writing and difference. Chicago: University of Chicago Press, 1986, p. 262 280.

SPIVAK, G. C. “Three women's texts and a critique of imperialism”. In: ASHCROFT, B.; GRIFFITHS, G.; TIFFIN, H. (Ed.). The post-colonial studies reader. London and New York: Routledge, 1995 , p. $269-272$. 